\title{
Linking visitors' spatial preferences to sustainable visitor management in a Norwegian national park
}

\author{
Sofie Kiendlie Selvaag, Øystein Aas \& Vegard Gundersen
}

Keywords: adaptive management, human disturbance, nature-based tourism, outdoor recreation, wildlife

\section{Abstract}

The increasing numbers of tourists visiting national parks contribute to new opportunities as well as challenges. Alpine and Arctic national parks in Northern Europe are key habitats for vulnerable species such as wild reindeer (Rangifer tarandus tarandus), and there is a significant need for management tools that can reduce the negative impacts of tourism. To gain knowledge about visitors' motivations and spatial preferences, we carried out a survey of people $(n=498)$ on paths in part of Rondane National Park, Norway. The results indicate that a large share of the visitors in the central, vulnerable part of the National Park may find their desired recreational benefits in the less vulnerable fringe entrance areas. We discuss theoretical and practical implications of the results and how to increase knowledge about visitors' spatial preferences in order better to regulate their behaviour with the aim of reducing impacts on vulnerable fauna.
Profile

Protected area

Rondane National Park

Mountain range

Rondane

Country

Norway

\section{Introduction}

The increasing demand for visiting and experiencing protected areas, including national parks (NPs), requires management actions that combine protection of key natural and cultural resources with provision of high-quality user experiences (Manning 2017). Nordic NPs represent a specific type of remote natural landscape and attract increasing attention from both local and international visitors (Hammer 2008). At the same time, many alpine and arctic NPs of the Nordic countries are key habitats for mammal and bird species of special conservation concern. One such species is the reindeer, Rangifer tarandus tarandus, the last remaining European populations of which are found in southern Norway (Kjørstad et al. 2017).

Consequently, there is a significant need for efficient tools that can help managers to avoid negative impacts of tourism and recreation on vulnerable fauna, including disturbance and loss of habitat (Larson et al. 2016; Kjørstad et al. 2017). In the last 50 years, land development in mountain areas for infrastructure and tourism has drastically altered historical habitats and migration corridors for wild reindeer. The populations have been severely fragmented and the process is ongoing, with unknown long-term consequences (Panzacchi et al. 2013a; Panzacchi et al. 2013b). In a major national science-policy document, Andersen and Hustad (2004) recommended modifying reindeer management by focusing more strongly on spatially-explicit issues related to land management, and by strengthening the human dimension in the management of wildlife to achieve sustainable reindeer management.

By carefully altering spatial regulations and managerial settings, NP managers should be able to avoid or reduce visitation at vulnerable places and times, while visitors still gain valuable experiences. NP management should today rely on adequate knowledge about visitors (Manning et al. 2017), which is also a legal requirement for knowledge-based management embedded in the Norwegian Nature Diversity Act (2009).

We examined three research questions related to knowledge-based visitor management in Rondane NP, which are also of relevance to other protected areas where interactions between visitors and vulnerable fauna must be managed:

1. What characterized visitors who preferred central and fringe areas, respectively, of the protected area?

2. What spatial management actions, recreational facilities and services were supported and opposed by the visitors?

3. What visitor segments were more responsive to information and interpretation about why some areas are vulnerable and not always suited for visitation?

Based on the findings, we discuss suitable management actions that can better accommodate tourists' experience expectations as well as the conservation needs of vulnerable fauna.

\section{Factors influencing visitors' behaviour}

The reasons for visiting a certain NP can be as diverse as the visitors themselves. They include individual factors (e.g. personality, preferences, attitudes, lifestyle, socio-demography), environmental or managerial factors (e.g. facilities, restrictions), and social factors (e.g. level of crowding, solitude, types of activities, accommodation) (Fredman \& Heberlein 2005; Haukeland et al. 2010; Gundersen et al. 2015). Important environmental factors attracting visitors to NPs are the outdoor recreation opportunities, landscape 
and scenery, natural resources such as wildlife, and unspoilt nature (Haukeland et al. 2010; Raadik et al. 2010; Vistad \& Vorkinn 2012).

Although many planning and management frameworks are goal-directed, allowing recreationists to pick and choose areas that will fulfil their expectations, there is little evidence for a clear correlation between people's experience preferences and the environmental, managerial and social settings of the places they visit (e.g. Pietila \& Kangas 2015). Based on a review of the literature and on a new survey, Hall et al. (2010) concluded that very few studies assess the effects of different management strategies on use and the subsequent impacts on the environment, including vulnerable species and their habitats. Most research, rather, is based on the hypothesis that meaningful visitor segments (for management purposes) will emerge when visitors are grouped according to their psychologi$\mathrm{cal} /$ individual motives. These visitor segments will seek places and settings that hold potential for them to fulfil their experience preferences and motivations (Manfredo et al. 1996; Manning et al. 2017).

Motivations for visiting NPs in Scandinavia are well studied (Aasetre \& Gundersen 2012), but the spatial hiking choices and alternatives inside these NPs have so far received less attention (but see Pietilä \& Kangas 2015; Raadik et al. 2010). The study by Raadik et al. (2010) on recreational experience preferences (REP) within Fulufjället NP emphasized that further research should examine differences between visitors across the park's different zones. A follow-up study on German visitors to Fulufjället NP found that individual and social factors are less important reasons to visit the area; more important are factors related to wildnerness experiences (Garms et al. 2017).

The REP scale aims to measure people's preferences and motivations associated with recreation in natural landscapes, such as solitude, experiencing nature, and achievement (Driver et al. 1991). Strongly linked to the REP scale is the Recreation Opportunity Spectrum (ROS) framework, which is applied to a spectrum ranging from wilderness areas to more developed areas. Outdoor recreationists can be placed along this gradient according to what kind of experience they prefer (Clark \& Stankey 1979; Driver \& Brown 1978). Pietilä and Kangas (2015) examined the relationship between recreational settings and visitor experiences in Oulanka NP in Finland. However, they found that different types of visitors, such as first-time and repeat visitors, had fairly similar setting preferences; several other site-specific studies have shown that there is little or no difference in REP scores across visitors to different ROS classes or places (Backlund \& Stewart 2012; Fix et al. 2013; Pietilä \& Kangas 2015).

Another related construct, the Wilderness Purism Scale (WPS), aims to measure visitors' preferences and attitudes to physical facilitation and social conditions for outdoor activities in natural areas (Vistad \& Vorkinn 2012). For instance, elements of facilita- tion such as paths, camps and footbridges tend to attract and concentrate visitors in certain areas. At the same time, this may affect the experience negatively for those who seek unspoilt nature and prefer solitude (Vistad \& Vorkinn 2012). Cole (2004) claims that the relationship between solitude and wilderness conditions is not straightforward, but a rather complex one.

In this study, we applied a more spatially explicit approach to measure and understand visitor behaviour and preferences for recreational sites in protected areas, aiming to circumvent some of the challenges with the REP, ROS and WPS approaches.

\section{Materials and methods}

\section{Study site}

The Rondane region covers a rugged mountain area and important reindeer habitat in central Norway. It is surrounded by multiple communities and smaller towns and settlements. Rondane NP, Norway's first (IUCN Category II), was established in 1962. The park covers $963 \mathrm{~km}^{2}$ and encompasses mostly remote alpine environments. The wild reindeer habitat covers all areas within the NP, as well as $1513 \mathrm{~km}^{2}$ of surrounding land. The study site, Høvringen, includes the park's north-west entrance area and covers approximately $230 \mathrm{~km}^{2}$ of the park $\left(61^{\circ} 52^{\prime} 11.7^{\prime \prime} \mathrm{N}\right.$, $9^{\circ} 37^{\prime} 38.8^{\prime \prime} \mathrm{E}$, Figure 1). The main recreational activity is mountain hiking in the summer; fewer people visit during winter, mainly to go cross country skiing. The most popular attraction in the study area is the Peer Gynt Cabin, located in the central wild-reindeer area (Strand et al.2014), yet accessible after a relatively short and easy hike of $4 \mathrm{~km}$ from the nearest gravel road.

Høvringen was chosen because it is very important for tourism in the region, and because some of the recreational uses in the study area conflict with wild reindeer migration paths (Strand et al. 2014). As illustrated in Figure 1, the development of recreational infrastructure and the intensive human use of marked paths has resulted in the reindeer becoming divided into two sub-populations. The hiking intensity on 12 path segments within the study site was estimated by applying a combination of automatic counters and GPS devices handed out to visitors at entrance points during the summer period 2009-2013 (Figure 1, Strand et al. 2014). The intensity of use on all marked paths is based on average levels of use and reflects the number of people (but not necessarily different individuals) walking a given trail segment (Figure 1).

\section{Sampling and data}

The target population was all visitors to the NP at Høvringen during the summer of 2016. Sampling was carried out by stopping visitors as they passed certain places along marked and unmarked paths within an area covering the main entrance at Høvringen (see Appendix for general characteristics). It was conducted over a period of 15 days during July and August. We 


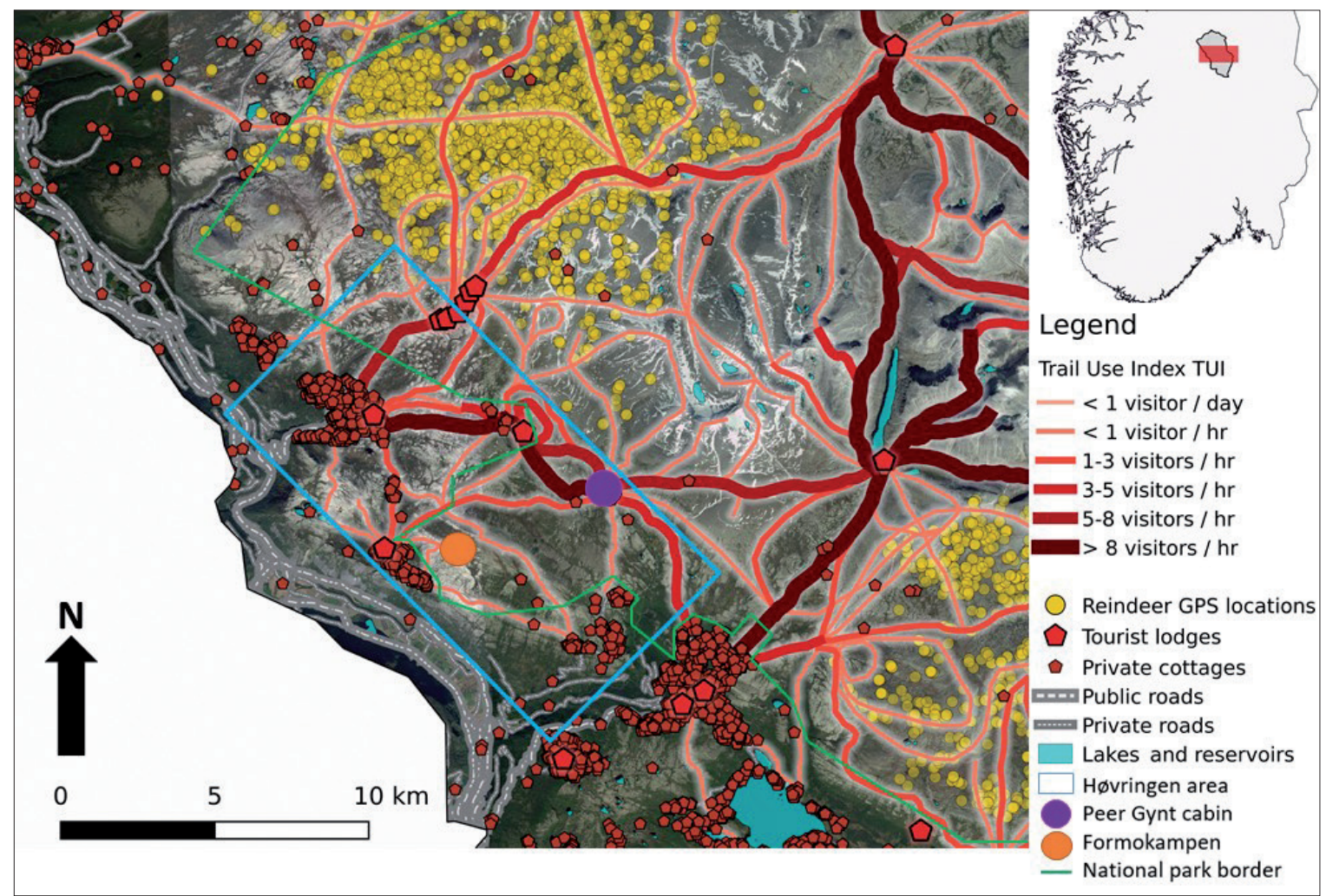

Figure 1 - Location of the study area; Hovringen fringe area (blue rectangle) and Peer Gynt Cabin (purple spot). For the period 2009-2013, the map indicates the main paths and the mean visitor volume in the course of a day during the peak tourist season (15 July to 15 August), and reindeer GPS positions (at 3-hour intervals), likewise during peak tourist season (35 GPS collared female reindeer) (from Strand et al. 2014). Data base: (C) 2019 Maxar Technologies, CNES / Airbus

interviewed visitors specifically 1) on the way to the Peer Gynt Cabin in the central, vulnerable area, and 2) visitors aiming for the Formokampen peak in the western fringe area of the NP (see Figure 1). Altogether, 498 respondents completed the questionnaire on site, a response rate of $96 \%$ of those asked to participate. Earlier surveys in the area indicate that the visitor profile in the area is fairly consistent throughout the summer season (Strand et al. 2014). Nevertheless, our sample should be considered one of convenience.

\section{Measures and statistics}

The new scale on spatial visitation preferences which we applied is both locally adapted and based on former studies regarding management, facilitation and social factors in the area (Kajala 2007). The factors that measured the spatial preferences for hiking areas (Table 1) were developed after inspection of the study area itself combined with qualitative, preparatory interviews with visitors, managers and tourist operators in the area. These interviews were semi-structured, based on open-ended questions, which allowed for spontaneity among the respondents. Their structure also allowed for the addition of questions in order to develop and refine the questionnaire further. The survey included measures of respondents' attitudes towards conservation of nature/wildlife, including their willingness not to visit vulnerable areas. For this latter dimension, we chose to use both a general conservation statement and a more specific item concerning disturbance to wild reindeer in the area. The new scale was a 7-point Likert scale, ranging from 1 completely disagree to 7 strongly agree, with 4 being neutral.

An exploratory factor analysis using varimax rotation was conducted on the new scale to identify the number of factors that could explain the underlying dimensions of the variables (Vaske 2008). Eigenvalues greater than 1 were set as criteria for variables representing qualities that may influence visitors' choice of recreational area. Further, an independent t-test was used to reveal differences in factor mean values for visitor segments, such as first-time and frequent visitors, locals and foreigners, and low-purists and high-purists (for description, see Appendix under Wilderness Purism Scale). Differences between groups were considered to be significant, at $\mathrm{p}<0.05$. All statistical tests were conducted using the software SPSS version 22.0.

\section{Results}

\section{Validation of the scale and identification of} main factors

The exploratory factor analysis showed that two of the original variables loaded on several factors. These items were It is important to feel that one is in the wilderness 

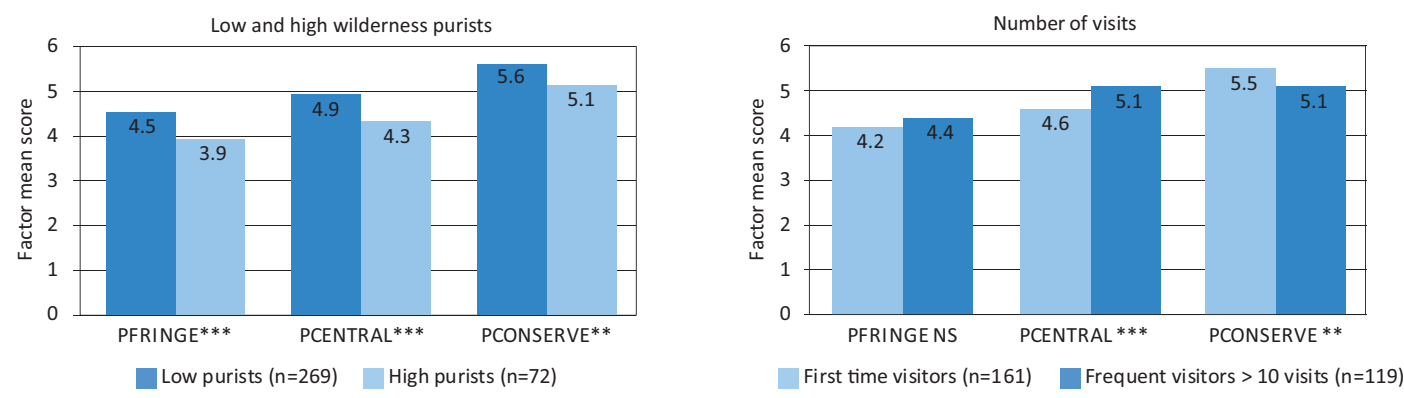

Figure 2 - Differences in mean value for the factors PFringe, PCentral and PConserve split between low wilderness purists and high wilderness purists (on left), and first-time visitors and visitors who have been to Rondane NP more than 10 times (right). *, ** and *** denote p-levels .05, .01 and .001. NS = no significant statistical difference at significance level $p<0.05$.

and It is appealing that the fringe areas are more adapted to tourism, and were omitted from the final factor analysis.

The factor analysis verified three factors (Table 1): preference $(\mathrm{P})$ for visiting / hiking in the fringe area (PFringe); visiting / hiking in the central area (PCentral); attitude and willingness to hike without affecting biodiversity negatively, thus conserving nature (PConserve). The reliability analysis of the factors yielded a satisfactory Cronbach's alpha between 0.61 and 0.73 (see Table 1 and Vaske 2008). Overall, the three factors explained $65 \%$ of the total variance.

Assessment by visitor segments of Rondane NP and responses to management actions

Overall, the score was highest for the PConserve factor and lowest for the PFringe. Significant differences in the mean score for all of the factors were found between low and high purists (Figure 2, left). Low purists were more positive towards all of the factors. The mean scores were also significantly different for the factors PCentral and PConserve between firsttime and frequent visitors ( $>10$ visits to Rondane NP) (Figure 2, right). Compared to less frequent visitors, these frequent visitors were more positive towards
PCentral. Further, first-time visitors agreed more with the factor PConserve.

There were no confirmed differences in mean score based on residence for the factor PFringe (Figure 3, left). This suggests that local users (respondents living in the neighbouring municipalities or having a cabin in the area), other Norwegians and foreigners consider the fringe area in Rondane NP equally attractive. Foreign respondents had the highest average value for PConserve. Local respondents considered the central area to be more attractive than the other groups did (Figure 3, left). This may be in relation to their felt connection to Rondane: the respondents who felt a strong connection to Rondane had a higher average score for the factor PCentral. Locals $(\mathrm{M}=6.0, \mathrm{SE}=0.13)$ felt a stronger connection to Rondane than the other respondents did $(\mathrm{M}=3.5, \mathrm{SE}=0.11)(\mathrm{t}(496)=15.01$ $\mathrm{p}<0.001)$. Because foreigners had a higher average for PConserve, it was also expected that respondents who felt little or no connection to Rondane would have a higher average for PConserve. However, this was not the case, and no difference was found for felt connection for PConserve (Figure 3, right). However, we did identify a small but significant difference for PFringe

Table 1 - Mean score and results of factor analysis with factor loadings after varimax rotation for qualities that may affect the choice of biking area in Rondane NP. bold = higherpositive coefficients

\begin{tabular}{|c|c|c|c|c|}
\hline Items / Factors & Fringe area & Central area & Conserve nature & Mean score \\
\hline There is a greater variety of hikes in the fringe & 0.848 & 0.092 & 0.042 & 4.49 \\
\hline The hikes in the fringe are more attractive & 0.797 & 0.091 & 0.136 & 4.04 \\
\hline It is good that it is shorter to travel to the fringe & 0.731 & 0.211 & 0.021 & 4.37 \\
\hline It is important to get close to the Rondane mountain massif & 0.097 & 0.766 & 0.177 & 4.80 \\
\hline $\begin{array}{l}\text { It is important to visit the Peer Gynt cabin or other attractions in the central } \\
\text { parts }\end{array}$ & 0.135 & 0.749 & -0.082 & 4.87 \\
\hline It is important to visit the National Park itself & 0.175 & 0.661 & 0.348 & 4.55 \\
\hline It is important not to interfere/disturb a wild reindeer herd & 0.010 & 0.117 & 0.865 & 5.20 \\
\hline $\begin{array}{l}\text { It is important to reduce wear on vegetation/safeguard vulnerable species } \\
\text { and nature }\end{array}$ & 0.135 & 0.111 & 0.821 & 5.54 \\
\hline Eigen value & 2.757 & 1.420 & 1.062 & \\
\hline Explained variance (\%) & 34.46 & 17.75 & 13.27 & \\
\hline Cronbach alpha $\alpha$ & 0.73 & 0.61 & 0.67 & \\
\hline
\end{tabular}

$K M O=0.715$, Bartlett's Test of Sphericity 822.48, $p<0.001$; three factors explain $65.48 \%$ of the variance. Item scores measured on a scale from $1=$ very negative to $7=$ very positive. 


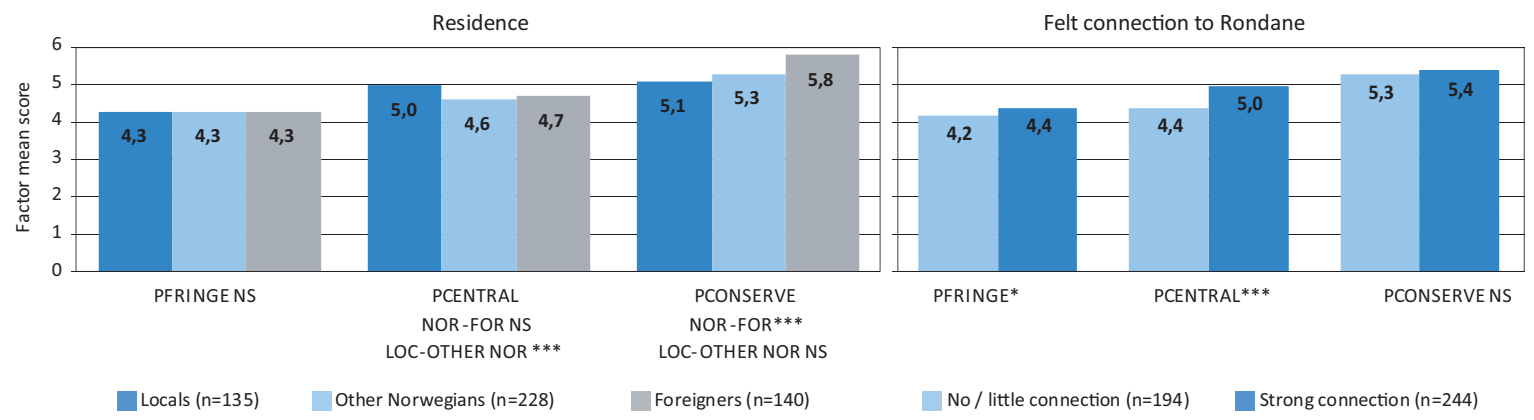

Figure 3 - Differences in mean value for the factors PFringe, PCentral and Pconserve, split between locals (respondents living in the neighbouring municipalities or having a cabin in the area), other Norwegians and foreigners (left), and respondents who felt either little or no connection to Rondane or a strong connection to Rondane (right). *, ** and *** denote p-levels .05, .01 and .001. NS =no significant statistical difference at significance level $p<0.05$.

between these segments. The respondents who felt a strong connection to Rondane also had a higher average for this factor.

\section{Discussion and conclusions}

In this study, we combined questions derived from motivational recreation research (Aasetre \& Gundersen 2012; Driver \& Brown 1978; Fredman \& Heberlein 2005; Kajala 2007; Vistad \& Vorkinn 2012), with place- and area-related questions regarding preferences for visiting sites in a national park. We used the results to analyse the relationship between recreational settings, the preference for visiting central and fringe areas, and the overall desired experience in Rondane NP. We show that it is possible to measure visitors' varied attitudes and behavioural intentions with regard to visiting fringe and central areas of a national park, and therefore suggest that a direct spatial approach to visitor management is a promising addition to the traditional psychographic approaches to manage for optimal experiences, especially in areas where there is particular concern for vulnerable species.

Our data confirms that the visitors to a national park do not form a homogeneous group (Fredman \& Heberlein 2005; Gundersen et al. 2015; Haukeland et al. 2010). The findings suggest that segments vary with regard to how easily they could be influenced by management efforts to use fringe or less vulnerable areas. This is related to knowledge and previous experience of outdoor recreation and of former use of, and attachment to, the area (Fredman \& Heberlein 2005; Gundersen et al. 2015). It is also related to personal preferences and motives for visiting an area (Clark \& Stankey 1979; Manning et al. 2017). Foreigners and first-time visitors were more positive towards the factor PConserve. Because they have no prior experience in the area, the results suggest that these groups could be managed easily and efficiently, and steered towards less vulnerable areas through targeted information and recreational facilitation (Fredman \& Heberlein 2005).
The high-purist segment includes wilderness visitors who want more solitude and less facilitation. Fix et al. (2013) suggest that those, such as foreign visitors and adventure seekers, who prefer more primitive ROS-classes have lower normative standards for crowding (see also Vistad \& Vorkinn 2012). For those who score high on the wilderness purism scale, it is important to manage fringe areas for recreational activities involving less facilitation.

The most difficult group to manage spatially in terms of lowering impacts on wild reindeer seems to be visitors who gave a high score to PCentral and a low score to PFringe. These visitors consider the fringe areas as of little relevance and appeal compared to the mountain summits in the central parts. This group needs to be studied more carefully in order to provide them with more opportunities for their desired experiences. A high proportion of these visitors have a strong connection to the place and visit Rondane frequently (local users, cabin owners etc.). They are less influenced by changes in recreational management and facilitation and can be a challenge to move to less vulnerable parts of the NP (Fix et al. 2013; Gundersen et al. 2015).

The most popular attraction in the study area is the Peer Gynt Cabin, located in the central wild-reindeer area. In combination with nearby spectacular mountain summits, the cabin attracts largely foreign and first-time visitors, but the cabin is also popular among frequent visitors scoring high on the PCentral factor. As such, this attraction represents a key management challenge if reduced visitation in this central area is to be achieved. This underlines that knowledge of placerelated features such as scenery and attractions is crucial when examining the reasons for hiking choices inside a recreational area (Pietilä \& Kangas 2015). The Peer Gynt Cabin offers limited services (accommodation, opening times, food etc.); providing cabins with better service levels in the fringe area may to some extent limit visits to the Peer Gynt Cabin.

Based on our findings, we suggest a more explicit spatial segregation strategy to shield important areas 
for vulnerable fauna from visitor impacts, channelling the heaviest use to limited designated locations. This reflects spatial management approaches like those of the ROS framework (Aasetre \& Gundersen 2012). Our findings, however, recommend research to include more direct investigation into visitors' preference for, and willingness to visit, replacement locations in protected areas. Developing this approach further would enable us to assess empirically the potential for substituting vulnerable (central) areas with more resilient (fringe) ones as destinations for visits.

Indirect measures are also all-important for channelling visitors towards fringe areas (Gundersen et al. 2015). Such measures include visitor information and service centres, developing simple recreational facilities like marked paths, shelters, bridges, viewpoints and short circular walks to unique places in the fringe entrance areas. Since many of the visitors in our study requested mountain summit scenery, management authorities need to consider developing well-designed viewpoints in the fringe areas. It is also likely that many visitors were largely unaware of the issue of human disturbance of wild reindeer, and consequently did not use this as a factor when making decisions about where to go in Rondane NP. Providing essential information about wild reindeer, especially immediately before the hiking route is chosen, could potentially change visitors' spatial use of the area, as most of them express respect for management and conservation recommendations (Gundersen et al. 2015).

The strength in our study is that we extracted three factors from our data (PCentral, PFringe, PConserve) that deal with choice of hiking area and willingness to respond and adapt recreational behaviour to conservation challenges. These factors should be developed further and customized to other areas where spatial approaches to visitor management are relevant. Nevertheless, it must be acknowledged that the factors affecting the quality of experience and spatial choices are complex, and they include subjective evaluations and not actual behaviour. Using objective environmental variables (like attractions, recreational services and facilities etc.) could provide only supplementary (not core) explanations for visitors' nature experiences. However, since few studies approach the segmentation of visitors from a spatial / geographic perspective, our approach should be subjected to further tests and development for verification and improvement. It should also, of course, be applied in studies in other recreational areas, especially in protected areas where conflicts exist between the desires of tourists and the needs of vulnerable species.

\section{Acknowledgements}

We want to thank the anonymous reviewers for their constructive criticism and suggestions on how to clarify our arguments. The Research Council of Norway funded this research within project 230335 ADMAN.

\section{References}

Aasetre, J. \& V. Gundersen 2012. Outdoor recreation research: Different approaches, different values? Norwegian Journal of Geography 66: 193-203. DOI: 10.1080/00291951.2012.707987

Andersen, R. \& H. Hustad (eds.) 2004. Villrein \& Samfunn. [Wild reindeer \& society]. NINA booklet 27. Trondheim, Norway. [In Norwegian]

Backlund, E.A. \& W.P. Stewart 2012. Effects of setting-based management on visitor experience outcomes: Differences across a management continuum. Journal of Leisure Research 44(3): 392-415. DOI: 10.1080/00222216.2012.11950271

Clark, R. \& G. Stankey 1979. The recreation opportunity spectrum: A framework for planning, management and research. USDA Forest Service Research Paper PNW-98.

Cole, D.N. 2004. Wilderness experiences: what should we be managing for? International Journal of Wilderness 10(3): 25-27.

Driver, B.L. \& P.J. Brown 1978. The recreation opportunity spectrum concept and behavioural information in outdoor recreation resource supply inventories: A rationale. (Edited by HG Lund et al.). USDA Forest Service, General Technical Report (RM-55): 24-31.

Driver, B.L., H.E.A. Tinsley \& M.J. Manfredo 1991. The paragraphs about leisure and recreation experience preference scales: Results from two inventories designed to assess the breadth of the perceived psychological benefits of leisure. In: Driver, B.L., P.J. Brown \& G.L. Peterson (eds.), Benefits of Leisure: 263286. Venture, State College, PA.

Fix, P. J., J. Carroll \& A.M. Harrington 2013. Visitor experiences across recreation settings: A management or measurement issue? Journal of Outdoor Recreation and Tourism 3: 28-35. DOI: 10.1016/j.jort.2013.09.003

Fredman, P. \& T.A. Heberlein 2005. Visits to the Swedish mountains: Constraints and motivations. Scandinavian Journal of Hospitality and Tourism 5: 177-192. DOI: 10.1080/15022250500266583

Garms, M., P. Fredman \& I. Mose 2017. Travel motives of German tourists in the Scandinavian mountains: the case of Fulufjället National Park. Scandinavian Journal of Hospitality and Tourism 17(3): 239-258. DOI: $10.1080 / 15022250.2016 .1176598$

Gundersen, V., M. Mehmetoglu, O.I. Vistad \& O. Andersen 2015. Linking visitor motivation with attitude towards management restrictions on use in a national park. Journal of outdoor recreation and tourism 9: 77-86. DOI: 10.1016/j.jort.2015.04.004

Hall, T.E., E. Seekamp \& D. Cole 2010. Do recreation motivations and wilderness involvement relate to support for wilderness management? A segmentation analysis. Leisure sciences 32(2): 109-124. DOI: 10.1080/01490400903547096

Hammer, R.B. 2008. Recreation and rural development in Norway: Nature versus culture. Scandinavian 
Journal of Hospitality and Tourism 8(2): 176-186. DOI: 10.1080/15022250802091135

Haukeland, J.V., B. Grue \& K. Veisten 2010. Turning national parks into tourist attractions: Nature orientation and quest for facilities. Scandinavian Journal of Hospitality and Tourism 10(3): 248-271. DOI: 10.1080/15022250.2010.502367

Kajala, L. 2007. Visitor monitoring in nature areas: $A$ manual based on experiences from the Nordic and Baltic countries. Nordic Council of Ministers.

Kjørstad, M., S.W Bøthun, V. Gundersen, Ø. Holand, K. Madslien, A. Mysterud, I.N Myren, T. Punsvik, K.H. Røed, O. Strand, T. Tveraa, H. Tømmervik, B. Ytrehus \& V. Veiberg 2017. Miljokvalitetsnorm for villrein - Forslag fra en ekspertgruppe. [Environmental quality standard for wild reindeer - Suggestions from an expert group]. NINA Report 1400. [In Norwegian]

Larson, C.L., S.E Reed, A.M Merenlender \& K.R Crooks 2016. Effects of Recreation on Animals Revealed as Widespread through a Global Systematic Review. PLoS ONE 11(12). DOI: 10.1371/journal. pone.0167259

Manfredo, M.J., B.L. Driver \& M.A. Tarrant 1996. Measuring leisure motivation: A meta-analysis of the recreation experience preference scales. Journal of Leisure Research 28(3): 188-213. DOI: 10.1080/00222216.1996.11949770

Manning, R.E., L.E. Anderson \& P. Pettengill (eds.) 2017. Managing outdoor recreation: case studies in the national parks. DOI: 10.1079/9781786391025.0003

Norwegian Nature Diversity Act 2009. Act of 19 June 2009 No.100. Relating to the management of biological, geological and landscape diversity. Available at: http://www.regjeringen.no/en/doc/Laws/Acts/ nature-diversity-act.html?id $=570549(01.07 .2018)$

Panzacchi, M., B. Van Moorter, P. Jordhøy \& O. Strand 2013a. Learning from the past to predict the future: using archaeological findings and GPS data to quantify reindeer sensitivity to anthropogenic disturbance in Norway. Landscape Ecology 28(5): 847-859. DOI: $10.1007 /$ s10980-012-9793-5

Panzacchi, M., B. Van Moorter \& O. Strand 2013b. A road in the middle of one of the last wild reindeer migration routes in Norway: crossing behaviour and threats to conservation. Rangifer 33(2): 15-26. DOI: 10.7557/2.33.2.2521

Pietilä, M. \& K. Kangas 2015. Examining the relationship between recreation settings and experiences in Oulanka National Park - A spatial approach. Jour- nal of Outdoor Recreation and Tourism 9: 26-36. DOI: 10.1016/j.jort.2015.03.004

Raadik, J., S.P. Cottrell, P. Fredman, P. Ritter \& P. Newman 2010. Understanding recreational experience preferences: application at fulufjället national park, Sweden. Scandinavian Journal of Hospitality and Tourism 10(3): 231-247. DOI: 10.1080/15022250.2010.486264

Strand, O., V. Gundersen, P. Jordhøy, R. Andersen, I. Nerhoel, M. Panzacchi \& B.F. Van Moorter 2014. Villrein og ferdsel $i$ Rondane. Sluttrapport fra GPS-merkeprosjektet 2009-2014. [Wild reindeer and people in Rondane. Final report from the GPS-collar project 2009-2014]. NINA Report 1013. [In Norwegian]

Vaske, J.J. 2008. Survey research and analysis: Applications in parks, recreation and human dimensions.

Vistad, O.I. \& M. Vorkinn 2012. The Wilderness Purism Construct - Experiences from Norway with a simplified version of the purism scale. Forest Policy and Economics 19: 39-47. DOI: 10.1016/j.forpol.2011.12.009

\section{Authors}

Sofie Kjendlie Selvaag ${ }^{1}$ - corresponding author has worked with visitor surveys and on research supporting management in national parks, outdoor recreation and nature-based tourism. She also conducts research on sustainable tourism development. Email: sofie.selvaag@nina.no

\section{Øystein Aas $^{1,2}$}

is a research director at the Norwegian Institute for Nature Research in Norway (NINA), and adjunct professor at the Norwegian University of Life Sciences. His main research interests concern human dimensions of fisheries and wildlife, conservation conflicts, and social acceptance of renewable energy.

\section{Vegard Gundersen ${ }^{1}$}

works in particular on recreational monitoring, human disturbance and impact, carrying capacity, limits of acceptable change, and management of national parks and other outdoor recreation areas.

\footnotetext{
${ }^{1}$ Norwegian Institute for Nature Research, Vormstuguvegen 40, 2624 Lillehammer, Norway.

${ }^{2}$ Norwegian University for Life Sciences (NMBU), Faculty for Environment and Natural Resource Management. 1432 Ås, Norway.
} 


\section{Appendix}

Table A1 - Respondents' general characteristics, use of and connection to Rondane National Park $(n=498)$.

\begin{tabular}{|c|c|c|}
\hline Variable & Segmentation & Percent [\%] \\
\hline Nationality & $\begin{array}{l}\text { Locals } \\
\text { Other Norwegians } \\
\text { Foreigners }\end{array}$ & $\begin{array}{l}27 \\
46 \\
28\end{array}$ \\
\hline Gender & Men & 47 \\
\hline Age & \begin{tabular}{|l|}
$15-24$ \\
$25-34$ \\
$35-44$ \\
$45-54$ \\
$55-64$ \\
Over 64 \\
\end{tabular} & $\begin{array}{l}11 \\
16 \\
17 \\
24 \\
21 \\
11\end{array}$ \\
\hline Knowledge about the hike gained from: & $\begin{array}{l}\text { Friends/relatives/acquaintances } \\
\text { Tourism businesses } \\
\text { Internet } \\
\text { Travel book } \\
\text { Brochure } \\
\text { In other way } \\
\end{array}$ & $\begin{array}{r}52 \\
10 \\
15 \\
6 \\
4 \\
13\end{array}$ \\
\hline Average number of annual mountain hikes $(>3 \mathrm{~h}$ ) & $\begin{array}{l}0-1 \\
2-10 \\
\text { More than } 10\end{array}$ & $\begin{array}{l}10 \\
58 \\
32\end{array}$ \\
\hline Previous experience of Rondane NP & $\begin{array}{l}\text { First-time visitors } \\
1-10 \text { visits } \\
\text { More than } 10 \text { visits }\end{array}$ & $\begin{array}{l}32 \\
44 \\
24\end{array}$ \\
\hline Type of accommodation & $\begin{array}{l}\text { Visiting friends / family in the area } \\
\text { Private cabin owned by informant or near family } \\
\text { Rented tourist cabin or hotel } \\
\text { Live nearby permanently } \\
\text { Tent } \\
\text { Camper / caravan } \\
\text { Passing trough/day trip } \\
\text { Other types }\end{array}$ & $\begin{array}{r}10 \\
19 \\
47 \\
5 \\
7 \\
7 \\
4 \\
1 \\
\end{array}$ \\
\hline Type of hike & $\begin{array}{l}\text { Carwalk }(<2 \mathrm{~h}) \\
\text { Day trip }(2-10 \mathrm{~h}) \\
\text { Stay at the same accommodation and take hikes from there } \\
\text { Multiple-day hike }\end{array}$ & $\begin{array}{r}10 \\
39 \\
43 \\
9\end{array}$ \\
\hline Where they walk on this hike & $\begin{array}{l}\text { Gravel road/tractor road } \\
\text { Marked trail } \\
\text { Unmarked trail }\end{array}$ & $\begin{array}{r}4 \\
94 \\
2\end{array}$ \\
\hline Number of people hiking together & $\begin{array}{l}\text { Hiked alone } \\
2 \text { (including the respondent) } \\
3-5 \text { (including the respondent) } \\
\text { More than } 5 \text { (including the respondent) }\end{array}$ & $\begin{array}{r}3 \\
40 \\
43 \\
14\end{array}$ \\
\hline Children on the hike & $\begin{array}{l}\text { No children } \\
\text { Children }\end{array}$ & $\begin{array}{l}70 \\
30\end{array}$ \\
\hline
\end{tabular}

\section{Wilderness Purism Scale}

six items covered attitudes towards specific facilities; two items covered social attitudes. (For review and methodology, see Vistad \& Vorkinn 2012.) The attitudes were measured using a 7-point Likert scale, ranging from 1 very negative to 7 very positive, with 4 being neutral. The reliability test (Cronbach's Alpha) resulted in an acceptable covariance (Vaske 2008), of 0.72 , between the eight items. The mean, standardized value on the wilderness purism scale represents a continuum from 1 to 7 . However, it is usual to differentiate between low (1-3.5), medium (3.51-4.49), and high purists (4.5-7).

\section{Respondents' connection to the area}

measured using self-assessment using a 7-point Likert scale, ranging from 1 no special connection to 7 very strong connection. The respondents were further grouped into little or no connection (1-2.99), medium connection (3-4.99), and strong connection (5-7). They were also grouped into local, national and international visitors. Locals were either residents in the four adjacent municipalities (Vågå, Nord-Fron, Sel and Dovre), or visitors who owned a cabin within the study site. The survey also included standardized questions concerning visitors' demographic characteristics, their experiences of outdoor recreation, and their use of the area. 